\title{
Uso del mineral trióxido agregado (MTA) en dientes con formación apical incompleta
}

\author{
Use of the mineral trioxide aggregate (MTA) in teeth with apical incomplete formation
}

Lissete Liliana Mendoza Cama ${ }^{1 a b}$, Juvenal González León de Peralta1abc

\section{RESUMEN}

Se reporta el caso clínico de una niña de 8 años de edad, que llega a consulta presentando dolor intenso en la pieza dental 4.6, se realizó la toma de una radiografía periapical. El diagnóstico fue pulpitis irreversible sintomática en diente permanente joven con formación apical incompleta en estadio de nolla 8. Se decidió realizar el tratamiento de apicoformación, utilizando el Mineral Trioxido Agregado MTA como tope apical. Se realizaron los controles radiográficos al 1, 3,11, 35 meses y tomografía Cone Bean a los 43 meses de terminado el tratamiento. El paciente presentó ausencia de sintomatología clínica y radiográficamente se observaron depósitos de tejido óseo a nivel apical.

Palabras clave: Apexificacion; Mta; endodoncia. (Fuente: DeCS BIREME)

\section{ABSTRACT}

We report the clinical case of an 8-year-old girl who came to the clinic with intense pain in dental piece 4.6. Periapical radiography was taken. The diagnosis was symptomatic irreversible pulpitis in young permanent tooth with incomplete apical formation in null stage 8. It was decided to perform the apicoformation treatment, using the (MTA) Mineral Trioxide Aggregate: as an apical stop. The radiographic controls were performed at 1, 3, 11, 35 months and Cone Bean tomography 43 months after the end of treatment. The patient presented absence of clinical symptoms and, radiographically, deposits of bone tissue were observed at the apical level.

Key words: Apexification; Mta; Endodontics. (Source: MeSH NLM)

Recibido: 12 de julio de 2018

Aprobado: 29 de setiembre de 2018

Publicado: 28 de octubre de 2018

${ }^{1}$ Universidad de San Martín de Porres. Especialidad en endodoncia. Lima, Perú.

${ }^{a}$ Cirujano dentista, ${ }^{b}$ Especialista en Endodoncia ${ }^{c}$ Doctor en Odontolo

Correspondencia:

Lissete Liliana Mendoza Cama Correo: darlin157@hotmail.com
Este es un artículo Open Access distribuido bajo la licencia Creative Commons Atribución-NoComercialCompartir Igual 4.0

\section{\$(2)}




\section{INTRODUCCION}

El tratamiento más común para los casos de dientes con formación incompleta, es promover la apicoformación en este proceso se busca inducir la formación de una barrera de tejido calcificado con el objetivo de cerrar el ápice y permitir la obturación y sellado del sistema de conductos radiculares ${ }^{1}$

La literatura describe el uso de diversos métodos para promover la apicoformación, sin embargo las técnicas que preconizan el uso de pastas a base de hidróxido de calcio son las más difundidas; sin embargo, estas substancias se solubilizan dentro del conducto radicular de dientes con formación incompleta, tornando necesario el cambio periódico de la medicación intraconducto cada tres meses. El tratamiento de dientes con formación incompleta representa un reto para los odontólogos dado que estas piezas presentan paredes delgadas siendo más propenso a la fractura y la falta de un tope apical para la obturación.

La apexificación consiste en estimular la formación de una barrera calcificada en el ápice y que no completó la formación radicular. Esta barrera puede estar compuesta por dentina, cemento, hueso, u osteodentina. Para obtener el estímulo necesario para la formación de la barrera apical deben ser colocados materiales inductores dentro del conducto radicular ${ }^{2}$ Los procedimientos de regeneración en endodoncia se basan, biológicamente, en restaurar la función de la pulpa dañada por la estimulación de células madre o troncales existentes en el conducto radicular y/o la introducción y estimulación de nuevas células madre bajo condiciones favorables para su diferenciación, permitiendo reemplazar estructuras dañadas de la raíz y células del complejo dentino - pulpar (3)

Debido a las importantes funciones que cumple la vaina radicular epitelial de Hertwig en el desarrollo de las raíces después de la lesión pulpar, se debe hacer todo lo posible para mantenerla, pues proporciona una fuente de células indiferenciadas que podrían dar lugar a una mayor formación de tejido duro.(4)

En los últimos años ha sido preconizado el uso del MTA por su biocompatibilidad con la zona ósea gracias a que tiene la cualidad de formar puentes dentinarios, ser biocompatible, $\mathrm{pH}$ alcalino y que no favorece la inflamación, para casos de apexificación en las cuales se hace posible crear una barrera apical inmediata. ${ }^{1}$

\section{REPORTE DE CASO CLINICO}

Paciente femenino de 8 años de edad acude a la Clínica Universitaria de la Universidad de San Martin de Porres, Hcl: 2013004816 al servicio de endodoncia por presentar una "dolor en el dientecito", La historia médica refiere que no padece de ningún antecedente de enfermedades, se encuentra localizada, orientado en tiempo, espacio y persona. En su historia odontológica reveló tratamientos previos sin complicaciones como restauraciones, profilaxis.

Radiográficamente se observó imagen radiolúcida en la pieza 4.6 (lesión apical en diente con ápice abierto) raíces con longitud mediana, conductos amplios y pérdida de la continuidad del espacio periodontal a nivel apical.

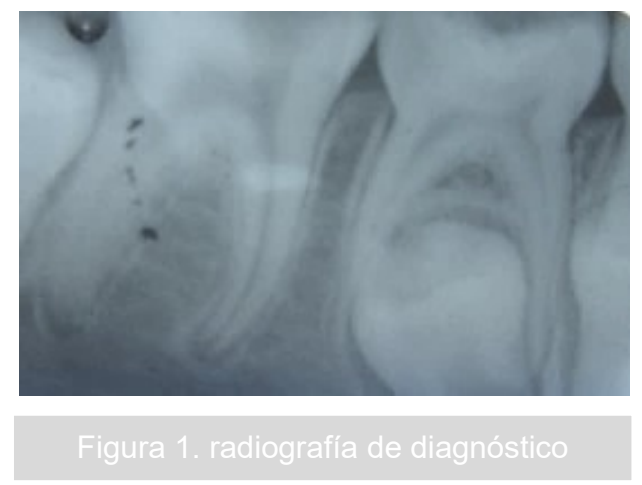

Posterior a la evaluación se confirma el diagnóstico presuntivo de pulpitis irreversible sintomática en diente joven con formación apical incompleta en la pieza 4.6 con estadio de nolla 8 , se le presento al paciente diferentes planes de tratamiento:

Plan N1 Apicoformación con hidróxido de calcio en piezas dental 4.6

Plan N² Apicoformación con MTA

Plan $\mathrm{N}^{\circ} 3$ Exodoncia de la pieza dental 4.6

Plan $\mathrm{N}^{\circ} 4$ tratamiento con pasta Triple (ciprofloxacino, metronidazol y minociclina)

Debido al diagnóstico de pulpitis irreversible sintomatica y se seleccionó el tratamiento de apicoformación con MTA y tratamiento de conductos con pronóstico reservado.

Se inició el tratamiento de conductos en la 1era cita, se procedió a iniciar el tratamiento de conductos con el aislamiento del campo operatorio previo la aplicación de 2 cartuchos anestésicos.

La apertura cameral fue realizada con una fresa redonda mediana, posterior fresa endozeta y el biselado de la cavidad se hizo con fresa troncocónica fina.

Fue seleccionada el uso de fresas Gates Glidden №2 y 3 para la preparación del tercio coronal de la raíz, se efectuó la Conductometría con limas tipo $\mathrm{K} \mathrm{N}^{\circ} 20$ para los conductos mesiales $\mathrm{N}^{\circ} 30$ determinándose la longitud de trabajo de los conductos, $18 \mathrm{~mm}$ en las mesiales y 20 en distales, tomando como referencia la odontometría. 
Se realizó la preparación de los conductos, se irrigó en pocas cantidades con hipoclorito de sodio $0.5 \%$ como irrigación inicial posterior suero fisiológico durante la instrumentación entre lima y lima hasta un número de lima 45 para los conductos distales y hasta un numero 35 para los conductos mesiales, una vez conformado los canales en su totalidad se procedió a secar los canales con conos de papel estériles siguiendo la medida de la conductimetría.

Se procedió a preparar pasta de hidróxido de calcio con vehículo acuoso (anestésico) como medicación intraconducto, dicha pasta fue introducida en cada conducto con ayuda de una lima con movimientos antihorario y su posterior compactación fue realizada con conos de papel estériles para remover toda humedad de la pasta hasta el tercio apical de la raiz.

Se realizó el sellado coronal de manera provisional con cemento de policarboxilato con la medicación de hidróxido de calcio dentro de los conductos, se le medicó al paciente con ibuprofeno de $100 \mathrm{mg} 5 \mathrm{ml}$, cada 6 horas durante 3 días.

En la segunda cita, se efectuó la remoción de la medicación a base de hidróxido de calcio con abundante irrigante (suero fisiológico) luego fueron secados todos los conductos con conos de papel.

Luego se realizó la colocación de MTA con limas tipo $\mathrm{K}$, posteriormente siendo empujados con conos de papel hacia apical creando un tapón apical de MTA de 3 a $4 \mathrm{~mm}$, tomando radiografía repetidas veces para verificar la ubicación del MTA en apical, posteriormente se coloca un algodón estéril en coronal y cemento de policarboxilato como provisional.

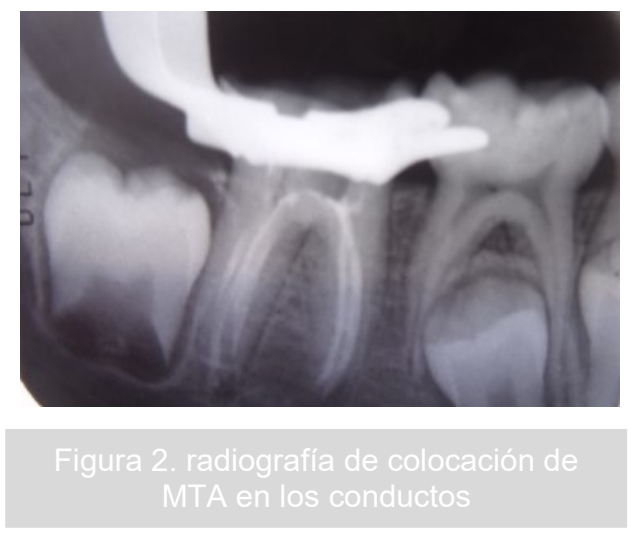

En la tercera cita tras comprobar el endurecimiento del material se colocaron los conos principales iguales a los número de limas memorias, se tomó la radiografía de conometría para luego realizar la obturación en frío mediante la técnica de obturación de condensación lateral, se preparó el cemento Endofill con una buena consistencia y con este fueron embadurnados los conos de gutapercha y fueron llevados respectivamente hacia el interior de los conductos.
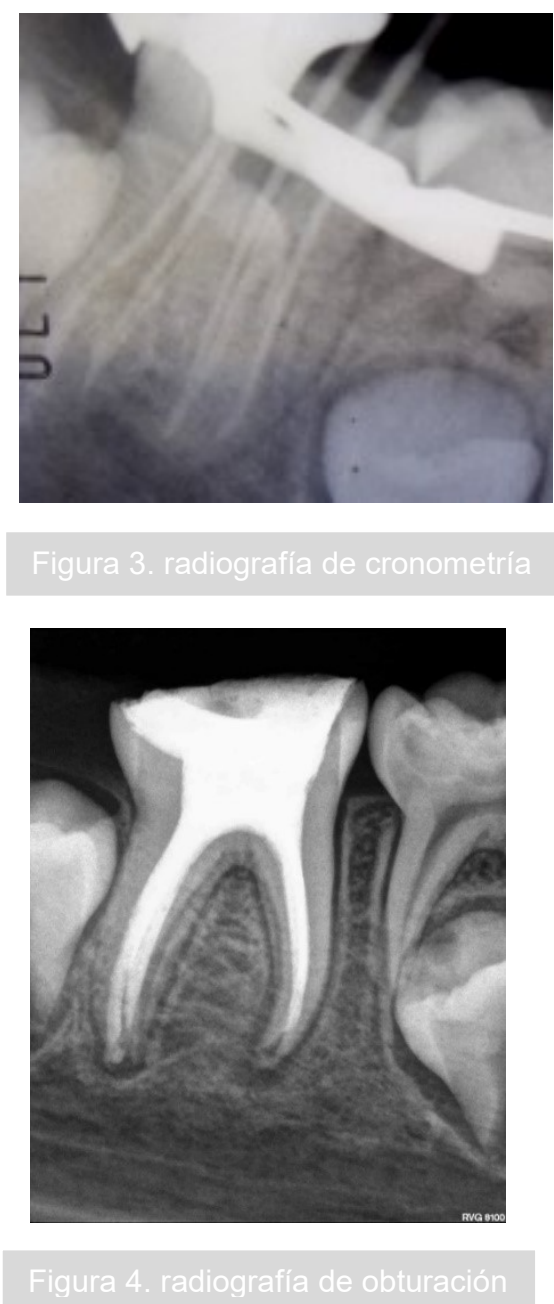

Finalmente se obturó provisionalmente con cemento de policarboxilato hasta la rehabilitación futura del diente, luego se procedió a tomar la radiografía de obturación final, notándose la obturación bien sellada y compactada, posterior a ello se derivó a clínica de pregrado para la colocación de una incrustación.

\section{RESULTADO DEL TRATAMIENTO}

Los resultados fueron muy positivos ya que el paciente fue colaborador en la asistencia de sus controles En este reporte de caso, concluimos tambien que el diente 4.6 se encuentra ausencia de sintomatología clínica. En el seguimiento de (1, 3, 11, 35 y 43 meses) se observó depósitos de tejido óseo.

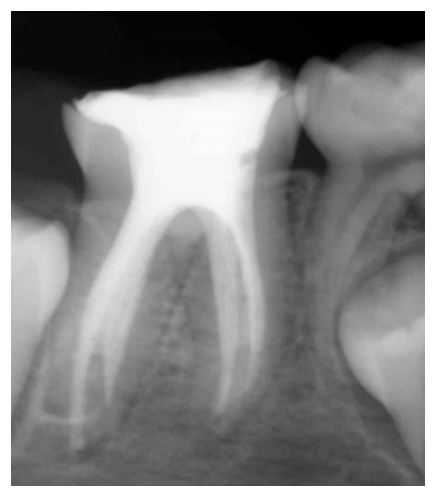



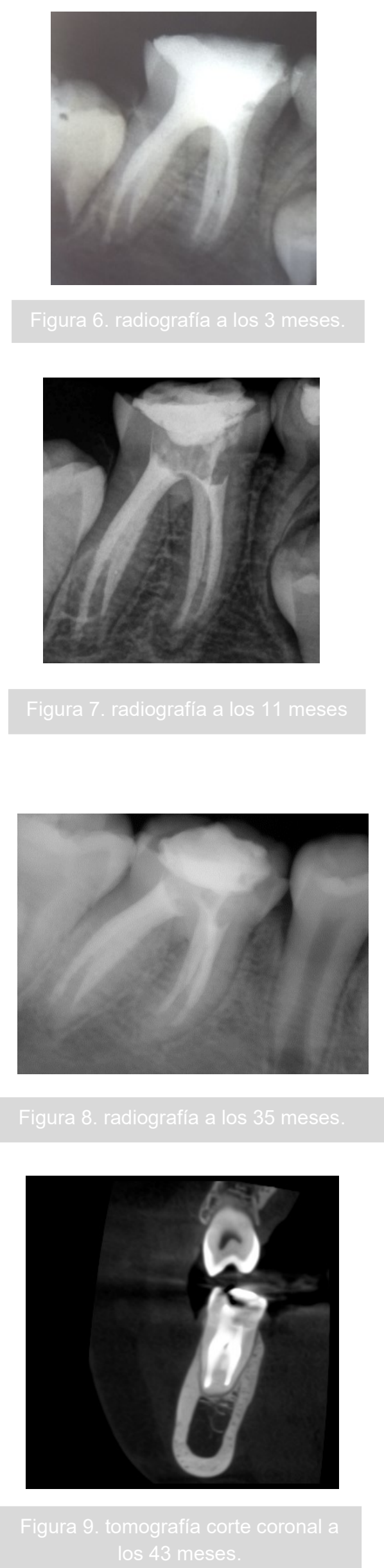
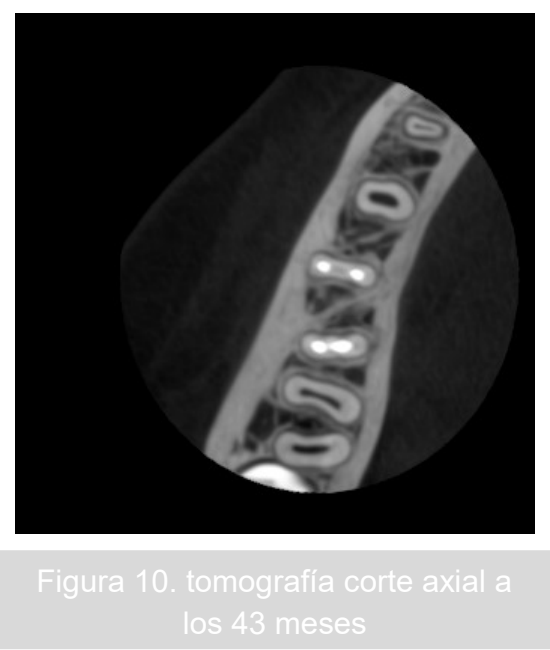

\section{DISCUSION}

El tratamiento de los dientes con ápices inmaduros tradicionalmente se realiza a través de una apicoformación con hidróxido de calcio, este procedimiento ha estado vigente por muchas décadas, en el cual se logra formar una barrera de tejido mineralizado en un periodo de tiempo largo, el objetivo de este trabajo fue realizar el tratamiento en un diente con formación apical incompleta utilizando un método que en la actualidad permite obtener una barrera dura apical seguido de una obturación de gutapercha, con un material biocompatible, que presente propiedades osteoinductivas y soporte la presencia de humedad (5). Murray 2007 menciona la endodoncia regenerativa; como un aspecto importante para estos casos la necesidad del uso de irrigantes intracanal $(\mathrm{NaOCl}$ y clorhexidina) con la colocación de los antibióticos (una mezcla de ciprofloxacino, metronidazol y minociclina) para conseguir la revascularización del conducto radicular, mediante una terapia de células madres, esta técnica de endodoncia regenerativa posiblementa implica alguna combinación de desinfección o el desbridamiento de los sistemas de canales de la raíces infectadas, con ensanchamiento apical para permitir la revascularización y el uso de células madre adulta y factores de crecimiento. ${ }^{(6)}$

Trope 2004 mencionó que, para controlar la infección se utilizaría la pasta poliantibiótica de ciprofloxacina, metronidazol y minociclina, en la que realizaron los procedimientos de revascularización y colocaron un sellado coronal con MTA hasta la unión cemento esmalte y resina para evitar la filtración bacteriana coronal. ${ }^{(7)}$

\section{CONCLUSIONES}

En este reporte de caso, concluimos que el diente 4.6 se encuentra ausencia de sintomatología clínica de enfermedad durante los controles del mes, tres meses, once meses y tres años.

En el seguimiento del caso (1, 3, 11, 35 y 43 meses) se observa depósitos de tejido óseo. 
Es de gran importancia seguir protocolos sobre tratamiento de apicoformación en pacientes pediátricos que tengan formación incompleta de sus dientes permanentes con lo que puedan comprometer el resultado de tratamiento de conductos.

Contribuciones de autoría: LLMC, JGLP diseñaron el estudio, recopilaron, analizaron los datos.

Redactaron y aprobaron el artículo todos los autores.

Fuente de financiamiento: El estudio fue financiado por los autores.

Conflicto de intereses: Los autores declararon no tener conflictos de interés.

\section{REFERENCIAS}

1. Villar Ayora A, Manejo endodontico de dientes con apices abiertos (tesis monografica pre grado). Lima. Universidad Peruana Cayetano Heredia; 2011.

2. Cardoso Pereira A, Rodrigo Herrera Morante D, Correia Laurindo de Cerqueira Neto A, Yuri Nagata G, Farias Rocha Lima T, Adriana de
Jesus Soares, Clinical alternatives for treatment of traumatized immature teeth: an update review Rev Estomatol Herediana. 2016 OctubreDic;26(4):271-80.

3. Moradas Estrada M, Alvarez López B. Ingenieria tisular y biomateriales en el tratamiento del diente con ápice inmaduro: revascularización revista europea de odontoestomatologia 2017 ver.php?id=264.

4. Hernán Coaguila Llerena, Antonio Denegri Hacking Apical barriers and apexifi cation in endodontics Rev Estomatol Herediana. 2014 Abr-Jun; 24(2):120-26.

5. Hamood E. The evaluation of success and failure of endodontic treatments. Aust Endod J. 2001; 27(2).

6. Murray P. Regenerative Endodontics: A Review of Current Status and a Call for Action. Journal of endodontics. 2007; 33(4).

7. Trope M. Revascularization of Immature Permanent Teeth with Apical Periodontitis: New Treatment Protocol? Journal of Endodontics. 2004; 30(4). 